\title{
Understanding Gender and Transgender
}

\author{
Dani Sia Choi', Bo Ra Park², Eun Sil Lee
}

${ }^{1}$ Korean Transgender Rights Organization Jogakbo; ${ }^{2}$ Department of Obstetrics and Gynecology, Soonchunhyang University Seoul Hospital, Seoul, Korea

\begin{abstract}
In the binary of gender, women and femininity came to be associated with motherhood, nurturing, and beauty whilst men and masculinity were associated with productivity, protection, and strength. No longer are we to systematically categorize an individual's gender in terms of polar opposite of femininity and masculinity, but instead we must acknowledge all that resides in between those two poles and allow for identity terms that best express their sense of self. The term 'transgender has become an umbrella term for a broader and more encompassing array of gender narratives outside of the binary norm of gender. Gender dysphoria is managed and treatable through psychotherapy and through the social and medical transition of gender. The support of transgender individuals' preferred gender through social acknowledgment, gender expression, hormone therapy, and surgery has been proven to alleviate symptoms of gender dysphoria in transgender people, enabling them to incorporate back into society.
\end{abstract}

Keywords: Gender identity; Transgender persons; Gender incongruence; Gender dysphoria

\section{INTRODUCTION}

With LGBTQ (lesbian, gay, bisexual, transgender, and queer)+ rights being at the forefront of activism in Europe and in North America, societies worldwide are becoming more aware of what it means to be transgender. Some form of legal transition from one gender to another is now possible in most of the American continent, Europe and in about half of the Asian countries [1]. Literature and research on the transgender population are now more prevalent than ever, and initiatives to better incorporate the healthcare of transgender patients are being undertaken by medical communities and transgender rights group alike. However, with this developing interest in the social and legal recognition of transgenderism, it is also important to consider the fact that the term 'transgender' now encompasses more identities than it once had. Transgender has become an umbrella term for a broader and more encompassing array of gender narratives outside of the binary norm of gender.

To be able to fully comprehend the notion of transgenderism, it is essential to understand notions such as gender identity and gen- der dysphoria. We are to elaborate on gender identity and gender dysphoria as well as looking at the prevalence of transgender people.

\section{GENDER IDENTITY}

Gender is an amalgamation of stereotypes created and adapted to better fit a specific societal purpose. One's gender carries the burden of perceived qualities and flaws and determines to a vast extent an entire aspect of one's identity. Though in and of itself, it may be culturally important and a cause for celebration, it has also been a source of vast injustice and a tool for oppression. Historically, in the vast majority of societies, this assignment of gender roles and expectations has overwhelmingly benefited those assigned and assumed men. Women's rights have only started to be recognized in the past century and this recognition has brought forth a multitude of economic developments [2].

Currently, much progress is being witnessed in the rights of women, and gender cannot be thought to be a culmination of past woes. But in the broad context of our gendered history, transgen- 
derism too, was understood, up until quite recently, in the frame of the binary. Individuals assigned male at birth experiencing gender dysphoria transitioned strictly into female and individuals assigned female transitioned strictly into male. This phenomenon of cross-gender transition by the transgender community has been accused by some feminist groups of purposefully enforcing negative gender stereotypes and contributing to the gender binary [3].

Existing gender identities today are recognized to be more intricate than the previously widely accepted binary of 'man' and 'woman.' A consensus of gender and feminist theorist has come to attribute gender as predominantly a social construct [4]. Thus, conception of femininity and masculinity would be fictitious realizations of roles prescribed by society wherein a system of reproductivity and sustainability would have been essential. Today gender and the expression of gender is better understood through a comprehensive and all-inclusive gender spectrum. No longer are we to systematically categorize an individual's gender in terms of polar opposite of femininity and masculinity, but instead we must acknowledge all that resides in between those two poles and allow for identity terms that best express their sense of self. Gender identity can consequently be defined by the one's personal experience with their own perceived gender [5]. Although natal sex can be assigned at birth, gender identity can only be assumed, and is not, in fact, known until an individual achieves a particular level of psychological development and self-awareness [6].

\section{DEFINITION OF GENDER INCONGRUENCE AND GENDER DYSPHORIA}

The term 'transsexual' became widely known after Benjamin [7] wrote "The transsexual phenomenon," but it was Hirschfeld [8] who coined the term 'transsexual' in 1923 to describe people who want to live a life that corresponds with their experienced gender versus their assigned gender. Instead of the term transsexualism, American Psychiatric Association uses the term gender dysphoria in its diagnosis of persons who are not satisfied with their assigned gender [9]. The World Health Organization (WHO)'s International Classification of Diseases 10th edition (ICD-10) still uses the term transsexualism when diagnosing people who feels their assigned gender uncomfortable. However, for the ICD-11, the WHO has proposed using the term 'gender incongruence' [10].

Gender incongruence is defined by a stronger identification with another gender than the gender assigned at birth [11]. Gender dysphoria refers to clinically significant distress related to the incongruence between one's affirmed or experienced gender and one's assigned or natal gender. This term replaces 'gender identity disorder' found in the earlier the diagnostic and statistical manual of mental disorders IV. Replacing 'disorder' with 'dysphoria' underscores the considered pathological, and instead, focuses on dysphoria as the clinical concern [12]. Transgender people experience a degree of gender incongruence; that is, a discordance between their personal sense of their own gender and the sex assigned to them at birth [13].

In adults, gender dysphoria leads to isolation, depression, poor self esteem and in some cases suicide. One study in the United States has found that out of 6,450 transgender people $41 \%$ had attempted suicide compared to the national average of $1.6 \%$. The transgender community is also reported to be at higher risks for mental disorders such as eating disorders [14].

Extensive studies have been carried out to determine the causes of gender incongruence and gender dysphoria. Much research has focused on the biological factors attempting to underline the innate nature of the transgender condition. Differences and similarities in brain structure between transgender women and cisgender, and transgender men and cisgender men have been examined in correlation to identity derived from sexuality. Environmental factors were also examined for the possibility of inciting gender dysphoria resulting in controversial theories such as the two distinct etiologies for androphilic and gynephilic transgender women put forward by Blanchard [15]. Despite the far-ranging intellectual interest in the matter, no conclusive cause has been found to explain the onset of gender dysphoria.

Gender dysphoria is managed and treatable through psychotherapy and through the social and medical transition of gender. The support of transgender individuals' preferred gender through social acknowledgment, gender expression, hormone therapy, and surgery has been proven to alleviate symptoms of gender dysphoria in transgender people, enabling them to incorporate back into society [16]. This process of gender affirmation commonly referred to as transitioning includes medical treatment of either feminizing or masculinizing hormone therapy and surgical treatment such as sex reassignment surgery, mastectomy, or breast augmentation surgery. However, not all transgender individuals experience gender dysphoria to the same extent. The degree to which a transgender person experiences gender dysphoria determines the course of their social and medical transition. A trans- 
gender person may or may not choose to undergo certain treatments according to their own sense of gender. For example, an male-to-female (MTF) identified transgender person may choose to receive hormone replacement therapy and gender affirmation surgeries whilst a non-binary gender individual may not choose to undergo any medical transition.

\section{GENDER DYSPHORIA OF ADOLESCENTS}

The onset of gender incongruence varies from individual to individual and with many transgender individuals, their gender identity remains undiscovered to them until later in life. However, with increasing amounts of literature and better education on gender and sexuality, the age at which one acts on their gender dysphoria is changing. Children and adolescents may express a wish to be the other sex and be unhappy about their physical characteristics. They may prefer the clothes and toys associated with the other gender and may choose to play with peers from the other sex. Untreated gender dysphoria in children and adolescents has been associated to disgust at their own body and genitalia, loneliness, social isolation as well as an increased risk of mental disorders. The American Psychological Association has stated that transgender children are more likely to experience harassment and violence in school, foster care, residential treatment centers, homeless centers, and juvenile justice programs than other children [17].

Today, many more treatment options are available to adolescents and children with gender dysphoria. Counselling and psychotherapy centered on gender may be offered to affirm a child's identity. Gender dysphoric adolescents may receive reversible and partially reversible cross sex medical treatment option. Reversible interventions include the use of gonadotropin-releasing hormone analogues to suppress estrogen or testosterone production to subsequently delay the physical changes of puberty. Partially reversible treatment interventions include hormone therapy to masculinize or feminize the body.

On the other hand, it must be taken into account that the pathologization and treatment of gender dysphoria in children has also been a source of controversy within the academic community since the 1980s [18]. Numerous studies have found that therapeutic intervention may help children and adolescents be more comfortable in their bodies and may prevent gender incongruence in adulthood. However, an important difference between gender dysphoric children and adolescents is in the proportion for whom dysphoria persist as an adult. Studies have found that children with gender dysphoria were much more likely to identify as homosexual in adulthood than as transgender [19]. Although, no formal prospective studies exist, it is estimated that gender dysphoria in adolescents is much more likely to persist into adulthood.

\section{PREVALENCE OF TRANSGENDER}

The prevalence of transgender people is difficult to accurately calculate as the definition of the term has grown to become much more inclusive than previously thought. Some transgender people choose not to transition medically and socially and some choose to only partially transition making it hard for researchers to separate transgender identities into categorizable variables. There is also very limited data on transgender and transsexual populations in any given location.

In a study carried out by psychiatrists and psychologist, a prevalence of 1:11,900 for MTF and 1:30,100 for female-to-male (FTM) was reported at the end of 1990 in the Belgium [20]. This data were derived from patients diagnosed as transsexual by mental health professionals.

In more recent studies, in which samples from the general population were asked about their gender identity, the estimates of people who identified as transgender ranged from $0.5 \%$ to $1.2 \%$ [21,22]. A Dutch study by Kuyper and Wijsen [23] analysed selfreported gender identity and dysphoria in a Dutch population sample $(\mathrm{N}=8064$, aged 15 to 70 years old $)$ and the results showed that $4.6 \%$ of people assigned male at birth and $3.8 \%$ of people assigned female at birth responded to have 'an ambivalent gender identity' (defined as equal identification with other sex as with sex assigned at birth) and $1.1 \%$ of people assigned male at birth and $0.8 \%$ of people assigned female at birth responded to have an incongruent gender identity'

Although prevalence data for transgender youth are lacking, multidisciplinary clinics for transgender youth and adolescents in Europe and North America have seen a steadily increasing demand for services in recent years [24-27], with a ratio of phenotypic males to females close to 1:1.

With advancements in technology enabling access to information about gender, people have had more opportunities to explore and find their gender identities. This would explain the surge in people identifying as transgender and gender non-binary in the 
past couple of decades. However, although access to critical information in identifying oneself may have become more available, the number of gender identities and terms have also expanded with the gradual dismantling of the gender binary. With these new non-binary identities spanning the whole gender spectrum, the challenge is to produce empirical data on categorizable groups. As no language exist as of yet to accurately classify gender non-binary identities, they cannot be compared and studied as easily as the binary MTF and FTM data. Moving forward, a better method of incorporating non-binary identities as a subgroup of transgender should have to be conceived.

\section{CONCLUSION}

The term transgender could be easily understood in the simplistic definition of identifying with the opposite gender. However, today, as we come to understand the complexities and history of gender, we may realize that there exist many intricacies in the experiences of transgender individuals and that one's experience of gender is a matter of subjecthood.

Dysphoria, and gender incongruence should neither be considered a pathological disease nor a compulsion but rather individuals experiencing such symptoms should be provided with appropriate support. The rising of societies' awareness on issues of gender will certainly enable individuals to realize their authentic identity sooner, leading to the possibility of more earlier treatment options. Much literature has been produced on the subject of transgender healthcare and research and studies have shown that counselling, and social and medical transition have proven greatly beneficial to the lives of transgender people. As such, the focus of the medical community, moving forward, would be to systematize and make more accessible services catering for the transgender community's needs.

Gender must no longer be understood in terms of binary opposites but rather celebrated in all of its forms and diversity. Attention and care must be given to the experiences of gender incongruence and gender dysphoria without prejudice. Perhaps then, we may see 'transgender' not as in transitioning from one gender to another but rather transcending the established forms of gender to create anew a true subjective identity.

\section{REFERENCES}

1. Trans Respect versus Transphobia Worldwide. Legal and social mapping [Internet]. Berlin: Transgender Europe; 2014 [cited 2018 Nov 20]. Available from: https://transrespect.org/en/research/legal-social-mapping/.

2. Doepke M, Tertilt M, Voena A. The economics and politics of women's rights. Annu Rev Econ 2012;4:339-72.

3. Raymond J. The transsexual empire. 2nd ed. New York (NY): Teachers College Press; 1994.

4. Lindsey LL. Gender roles: a sociological perspective. 6th ed. Boston (MA): Pearson; 2015.

5. Morrow DF, Messinger L. Sexual orientation and gender expression in social work practice: working with gay, lesbian, bisexual, and transgender people. New York (NY): Columbia University Press; 2006.

6. Rosenthal SM. Approach to the patient: transgender youth: endocrine considerations. J Clin Endocrinol Metab 2014;99:4379-89.

7. Benjamin H. The transsexual phenomenon. Trans N Y Acad Sci 1967;29: 428-30.

8. Hirschfeld M. Die intersexuelle konstitution. Jahrbuch fur Sexuelle Zwishenstufen 1923;23:3-27.

9. American Psychiatric Association. Diagnostic and statistical manual of mental disorders. 5th ed. Arlington (VA): American Psychiatric Association Publishing; 2013.

10. Drescher J, Cohen-Kettenis P, Winter S. Minding the body: situating gender identity diagnoses in the ICD-11. Int Rev Psychiatry 2012;24:56877.

11. Bouman WP, de Vries AL, T'Sjoen G. Gender dysphoria and gender incongruence: an evolving inter-disciplinary field. Int Rev Psychiatry 2016; 28:1-4.

12. Rosenthal SM. Transgender youth: current concepts. Ann Pediatr Endocrinol Metab 2016;21:185-92.

13. Winter S, Diamond M, Green J, Karasic D, Reed T, Whittle S, et al. Transgender people: health at the margins of society. Lancet 2016;388:390-400.

14. Grant JM, Mottet L, Tanis JE, Harrison J, Herman J, Keisling M. Injustice at every turn: a report of the national transgender discrimination survey. Washington (DC): National Center for Transgender Equality; 2011.

15. Blanchard R. The concept of autogynephilia and the typology of male gender dysphoria. J Nerv Ment Dis 1989;177:616-23.

16. Coleman E, Bockting W, Botzer M, Cohen-Kettenis P, DeCuypere G, Feldman J, et al. Standards of care for the health of transsexual, transgender, and gender-nonconforming people, version 7. Int J Transgenderism 2012;13:165-232.

17. Davidson MR. A nurse's guide to women's mental health. New York (NY): Springer Publishing Company; 2012.

18. Bartlett NH, Vasey PL, Bukowski WM. Is gender identity disorder in children a mental disorder? Sex Roles 2000;43:753-85.

19. Wallien MS, Cohen-Kettenis PT. Psychosexual outcome of gender-dysphoric children. J Am Acad Child Adolesc Psychiatry 2008;47:1413-23.

20. Van Caenegem E, Wierckx K, Elaut E, Buysse A, Dewaele A, van Nieuwerburgh F, et al. Prevalence of gender nonconformity in Flanders, Belgium. Arch Sex Behav 2015;44:1281-7.

21. Glen F, Hurrell K. Technical note: measuring gender identity. Manchester: Equality and Human Rights Commission; 2012.

22. Herman JL, Flores AR, Brown TN, Wilson BD, Conron KJ. Age of individuals who identify as transgender in the United States. Los Angeles (CA): The Williams Institute; 2017.

23. Kuyper L, Wijsen C. Gender identities and gender dysphoria in the Netherlands. Arch Sex Behav 2014;43:377-85. 
24. Zucker KJ, Bradley SJ, Owen-Anderson A, Kibblewhite SJ, Cantor JM. Is gender identity disorder in adolescents coming out of the closet? J Sex Marital Ther 2008;34:287-90.

25. De Vries AL, Cohen-Kettenis PT. Clinical management of gender dysphoria in children and adolescents: the Dutch approach. J Homosex 2012;59: 301-20.
26. Spack NP, Edwards-Leeper L, Feldman HA, Leibowitz S, Mandel F, Diamond DA, et al. Children and adolescents with gender identity disorder referred to a pediatric medical center. Pediatrics 2012;129:418-25.

27. Sherer I, Rosenthal SM, Ehrensaft D, Baum J. Child and adolescent gender center: a multidisciplinary collaboration to improve the lives of gender nonconforming children and teens. Pediatr Rev 2012;33:273-5. 